\title{
Comparison of sensitivity for the perception of bodily rotation and the oculogyral illusion'
}

BRANT CLARK AND JOHN D. STEWART

AMES RESEARCH CENTER, NASA

The purpose of this study was to compare the sensitivity of humans to angular acceleration using the perception of rotation and the perception of the oculogyral illusion as two indicators. Ten men with normal vestibular function were studied in a precision rotation device using a random, forced choice, double staircase method to determine the thresholds. The thresholds for the oculogyral illusion were found to be substantially and significantly lower than thresholds for the perception of rotation. The implications of these findings for an understanding of the oculogyral illusion are discussed.

Apparent motion of the visual field associated with rotation of the body has been reported in the literature since the late eighteenth century (Graybiel \& Hupp, 1946; Griffith, 1922) when it was known as visual vertigo. For the past 20 years, however, this type of apparent motion has been called the oculogyral illusion (Graybiel \& Hupp, 1946) or the optogyral illusion (van Dishoeck, Spoor, \& Nijhoff, 1954; Roggeveen \& Nijhoff, 1956) and has been widely used as an indicator of the function of the semicircular canals (Guedry, 1965). The oculogyral illusion may be defined as an apparent motion of objects in the visual field in the direction of stimulation by angular acceleration. Like visual autokinesis, the effect is characterized by a maximum of apparent motion and a minimum of apparent displacement of the objects in the visual field. With moderate to strong stimuli of appreciable durations, there may be a negative aftereffect when the acceleration is reduced to zero (Clark \& Stewart, in preparation (a); Graybiel \& Hupp, 1946). The optimum condition for perception of the phenomenon is the observation of an isolated, compiex visuai target in darkness with moderate to strong angular accelerations (Graybiel \& Hupp, 1946; Guedry, 1950). The observations may be complicated by visual autokinesis under these conditions.

There is some evidence that human os are more sensitive to the oculogyral illusion than to the simple perception of rotation, but only three studies have been found which have compared these two thresholds on the same Os (Christian, 1939; Hallpike \& Hood, 1953; Roggeveen \& Nijhoff, 1956). All of these investigations suffer from serious methodological limitations, notably in the inability to produce and measure accurately the angular accelerations used. For example, in the most recent study, the investigators did not immobilize $O$ 's head. They determined the angular acceleration as an average over time, and used only three high angular acceleration levels of $0.8 \mathrm{sec}$ duration to establish the threshold, the lowest being $1.25^{\circ} / \mathrm{sec}^{2}$. Consequently, it was the purpose of our experiment to compare the sensitivity of the semicircular canals in 10 men, using as indicators the perception of rotation and the perception of the oculogyral illusion while rotating them in a precision simulator.

\section{Apparatus}

\section{METHOO}

The Os were rotated in the Ames Man-Carrying Rotation Device (MCRD), a one-degree-of-freedom stimulator that rotates about a vertical axis up to $45 \mathrm{rpm}$ with continuous acceleration variations up to $30 \% / \mathrm{sec}^{2}$. The accelerations can be programmed and measured in $0.01 \% / \mathrm{sec}^{2}$ steps at the low velocities used. The accelerations were measured by on-board accelerometers, and the data from these and velocity sensors, as well as O's responses, were registered on an ink writing recorder. The cockpit turned on the shaft of a dc motor controlled by voltages programmed by an analog computer, making it possible to change acceleration with a rise time of the order of $0.1 \mathrm{sec}$. The simulator was essentially free of vibration which may be perceived by $O$ at the low velocities used during these threshold measurements. In addition, $O$ was unable to detect when he accelerated through zero velocity.

The $O$ sat erect in a lightproof cab, ventilated by two fans which also served to mask external noise. A headrest maintained $O$ 's head in a fixed position at the center of rotation while the aircraft harness and helmet were used as safety precautions. Communication between $O$ and $E$ was possible by interphone and signal switches.

\section{Observers}

The Os were 10 men who were in good health by their own affirmation (a general physical examination revealed no significant abnormalities). They all had normal hearing, and their responses to a caloric test were judged to be normal. Their thresholds for the perception of angular acceleration determined in a prior series of tests varied between $0.07^{\circ}$ and $0.76^{\circ}$ per $\sec ^{2}$ with a mean of $0.26^{\circ} / \mathrm{sec}^{2}$. These thresholds were below the mean of $0.43 \% / \mathrm{sec}^{2}$ for a group of 16 os studied earlier by a forced choice, 
random, double staircase procedure involving 120 observations of angular acceleration (Clark \& Stewart, in preparation, b).

\section{Procedure}

The $O$ sat erect during both of the test conditions with his helmet pressed firmly back against a U-shaped headrest to maintain his head in a fixed position. The angular accelerations were presented for $10 \mathrm{sec}$ in all trials. The direction of the acceleration was varied at random from trial to trial, and a minimum of $30 \mathrm{sec}$ elapsed between the end of one acceleration and the beginning of the next. A single series of 32 trials lasted about $30 \mathrm{~min}$, and at least $30 \mathrm{~min}$ elapsed between sessions. A $3-\mathrm{min}$ rest period was given halfway through each session. Preliminary practice sessions included observations of the perception of rotation and the oculogyral illusion. During the initial practice trials, Os were informed regarding the accuracy of their responses, but during the latter practice trials and all the reguiar trials, Os had no knowledge of results. The practice trials served to familiarize them with the oculogyral illusion and give a rough estimate of their sensitivity to the illusion. The order of collecting data alternated between sessions, five Os reporting the oculogyral illusion first and five reporting the perception of rotation first.

During the observations of rotation, $O$ sat in darkness with his eyes closed. His task was merely to indicate the direction of rotation by pressing the appropriate switch. To observe the oculogyral illusion, $O$ viewed a cube of wire making a frame $10 \mathrm{~cm}$ on each side mounted at eye level $4 \mathrm{ft}$ in front of $O$. The cube, painted with luminescent paint, was illuminated by ultraviolet light. The wire sections, which formed the back part of the cube, were painted black. Consequently, only nine edges of the cube were visible. The purpose of this complex form was to reduce autokinesis to a minimum, but it was only partly successful, as others have reported (Graybiel \& Hupp, 1946), since some Os reported vertical motion of the cube. $O^{\prime} s$ task was to indicate the direction of the apparent motion for each trial by pressing the right or left switch, disregarding any apparent vertical displacements.

The angular accelerations were presented following a forced choice, random, double staircase method similar to the methods described by Cornsweet (1962) and Heinemann (1961) and studied in detail by Clark and Stewart (in preparation (b)). The initial trials of the two staircases began at the same steps for eazh $O$ for the two conditions. In each case the upper staircase was begun five or six $0.1 \log$ unit steps above the highest threshold estimated from the preliminary trials, while the lower staircase began an equal number of steps below the lowest estimated threshold. Each step consisted of a pair of accelerations at a given level. If $O$ responded correctly on both observations, the next pair of accelerations was reduced two $0.1 \mathrm{log}$ unit steps. If one or both of the reports wore incorrect, the next pair of accelerations was increased by a similar amount. However, in the trials before the staircases crossed, a step of only one $0.1 \mathrm{log}$ unit was made if the step was taken in the direction to separate it from the other staircase. This procedure was designed to increase the rate of crossing the staircases (Cornsweet, 1962). After the staircases crossed or had a point in common, all steps were made in $0.2 \mathrm{log}$ unit steps except that an initial single step was made on one staircase, if necessary, to have the accelerations fall on adjacent rather than on the same levels. Trials alternated randomly between the two staircases within eight pairs of accelerations. The staircases were considered to have reached a "final level" on the next trial after a reversal of direction of each staircase had occurred following the mesting or crossing of the staircases. From this point, data were counted to determine the threshold. Eighty observations were made following this final level for each of the two conditions, and the mean of these accelerations was considered to be the threshold for each condition for each $O$.

\section{RESULTS}

The data show that these 10 Os were much more sensitive to angular acceleration when viewing an isolated cube in darkness than when they relied on vestibular stimuli alone. The threshold for the perception of rotation was nearly three times that for the perception of the oculogyral illusion (Table 1), the difference being statistically significant $(p<0.01)$. The variability was also substantially less for the oculogyral illusion (Table 1). The rank order correlation between the thresholds determined by these

Table 1. Comparison of thresholds for the perception of rotation and the perception of the oculogyral illusion for 10 men

\begin{tabular}{|c|c|c|}
\hline & $\begin{array}{c}\text { Oculogyral Iflusion } \\
\text { Threshold, \%/sec } 2\end{array}$ & $\begin{array}{c}\text { Perception of Rotation } \\
\text { Threshold, } / \sec ^{2}\end{array}$ \\
\hline $\begin{array}{l}\text { Mean threshold } \\
\text { (80 observations) }\end{array}$ & 0.10 & 0.29 \\
\hline $\begin{array}{l}\text { Range of thresholds } \\
\text { ( } 80 \text { observations) } \\
\text { Mean of first } 40\end{array}$ & $0.05 \cdot 0.18$ & $0.09-0.55$ \\
\hline $\begin{array}{l}\text { observations } \\
\text { Mean of second } 40\end{array}$ & 0.10 & 0.27 \\
\hline $\begin{array}{l}\text { Mean of individual } \\
\text { deviations betwee } \\
\text { first and second }\end{array}$ & 0.11 & 0.31 \\
\hline 40 observations & 0.03 & 0.14 \\
\hline \multicolumn{3}{|l|}{ Christian (1939) } \\
\hline$(N=?)$ & $0.13-0.33$ & $0.13-3.0$ \\
\hline \multicolumn{2}{|c|}{ Hallpike and Hood (1953) } & $0.6-2.0$ \\
\hline $\begin{array}{l}\text { Roggeveen and } \mathrm{Nijh} \\
(\mathrm{N}-15)\end{array}$ & ff (1956) 1.3 & 1.75 \\
\hline
\end{tabular}


two indicators was $\mathbf{- 0 . 2 3}$, which, for this small group, is not significantly different from zero. This low correlation is evident from a cursory examination of the individual thresholds; e.g., the $O$ with the highest threshold for the perception of rotation $\left(0.55^{\circ} / \mathrm{sec}^{2}\right)$ had the lowest threshold for the oculogyral illuston $\left(0.05^{\circ} / \mathrm{sec}^{2}\right)$. Again, if the Os were divided into two groups of five having the highest and the lowest thresholds on the basis of measurements made before this experiment began, marked differences were apparent. The mean thresholds for the high group for rotation and the oculogyral illusion were, respectively, $0.39^{\circ}$ and $0.08^{\circ}$ per $\sec ^{2}$, while those for the low group were $0.19^{\circ}$ and $0.13^{\circ}$ per $\sec ^{2}$, respectively. Thus, the group with the higher mean rotation threshold had a slightly lower threshold for the oculogyral illusion. Indeed, the two Os with the lowest thresholds for the perception of rotation showed slightly higher thresholds for the oculogyral illusion in the present study. It is evident, therefore, that the low mean threshold for the oculogyral illusion is a result of Os with relatively high rotation thresholds having much lower thresholds for the oculogyral illusion, while those with low rotation thresholds showed little difference.

Comparisons between the first and second 40 observations indicate that the means for the $10 \mathrm{Os}$ are stable over the 80 trials for both conditions (Table 1). The average of the individual deviations between the first and second 40 observations was, however, substantially less for the oculogyral illusion, indicating that this is a more stable measure (cf Guedry, 1965). The rank correlations between the first and second 40 trials for the oculogyral illusion and the perception of rotation were only moderate, being +0.57 and +0.72 , respectively. This again shows substantial individual variability, but the limited range of thresholds should be noted (Table 1).

\section{DISCussion}

Our results clearly support earlier studies in showing that the threshold for the oculogyral illusion is lower than that for the perception of rotation. At the same time, our os produced substantially lower values for both indicators than were reported in the three studies cited (Table 1). The very high thresholds reported by Roggeveen and Nijhoff (1956) can be understood in terms of the short stimulus duration $(0.8 \mathrm{sec})$. The low thresholds revealed by our Os are probably, in part, due to the fact that the Os were carefully selected to insure normal vestibular function. In addition, they had average rotation thresholds somewhat below the average of a small group of 16 normal Os studied recently (Clark \& Stewart, in preparation, b). This larger group had a mean threshold of about $0.40 \% / \mathrm{sec}^{2}$, which is also well below those reported in the earlier studies. Consequently, it would appear that our method produces low thresholds, in part, because the MCRD has excellent control of angular accelerations and very smooth operating characteristics. It may be noted that the threshold value for the oculogyral illusion closest to our mean threshold is that reported by Graybiel, Kerr, and Bartley (1948). This low value, too, may be due, in part, to the smoothness of the heavy flywheel on which they rotated their O's, although they were unable to program their accelerations for specified levels as was possible in the MCRD. These differences between the thresholds for the perception of the oculogyral illusion and the perception of rotation are consonant with the results observed in the cupulograms of the two effects. These data show that the duration of the oculogyral illusion is greater than the perception of rotation following suprathreshold accelerations (van Dishoeck et al., 1954; Mann \& Canella, 1956).

The results of this experiment raise certain questions regarding the nature of the oculogyral illusion. It is clear that the phenomenon is a result of the interaction of visual and vestibular information which is comparable to that in the oculogravic illusion (Graybiel \& Clark, 1965) and the interaction of auditory and vestibular information with the audiogyral illusion (Clark \& Graybiel, 1949). But what are the primary causes of the illusion? A theory proposed a number of years ago suggested that it was a result of vestibular nystagmus (Graybiel \& Hupp, 1946; Graybiel, Clark, MacCorquodale, \& Hupp, 1946), but this theory has been discounted by reports of the oculogyral illusion in Os with nonfunctional extraocular muscles and during observations of a stopped image (Byford, 1963; van Dishoeck et al., 1954; Howard \& Templeton, 1966). These authors propose that the primary causal factor is the perception of rotation. This simple explanation is appealing, but the perception of rotation, like nystagmus, may well be only a concomitant effect. This notion is supported by the fact that the thresholds for the oculogyral illusion are lower and the duration of the aftereffect longer than for the perception of rotation, but it is difficult to put the issue to a crucial test as in the case of nystagmus. Another explanation has been suggested by Whiteside, Graybiel, and Niven (1963). They propose "that the apparent movement is associated with efferent activity in the antagonist to the slow phase efferent activity present as a result of labyrinthine stimulus." This seems to be in accordance with the possibility that nystagmus, the perception of rotation, and the perception of the illusion produce different results because they are controlled by different levels of the central nervous system. In the case of the oculogyral illusion, there is an interaction between vestibular and visual centers which occurs in neither of the other effects.

A second question has to do with the factors which contribute to the longer aftereffect and the lower 
thresholds found with the oculogyral illusion. Howard and Templeton (1966) have proposed that the experimental operations with a visual target are conducive to the perception of a unidirectional autokinesis. Many reports have indicated that autokinesis does occur under these experimental conditions, and, indeed, one $\mathrm{O}$, following prolonged stimulation by angular acceleration, reported that the oculogyral illusion persisted for 5 or 6 min after the acceleration was reduced to zero on several trials. It is not possible, however, to distinguish unequivocally between the aftereffect of rotation per se and autokinesis when the movement is continuously in the same direction. Similarly, using visual autokinesis as an explanation does not offer an explanation why visual autokinesis is greater than what we have called gyroautokinesis, a perception of apparent rotation of the body in the absence of angular acceleration. Autokinetic effects appear to be involved in all such observations. Possible factors which contribute to the lower threshold for the oculogyral illusion have been listed (Clark, 1967) as follows: (1) The use of a visual target increases $O$ 's alertness; (2) $O$ has had more experience in observing visual movement than rotation in the absence of vision; and (3) a visual target supplies $O$ with additional sensory information, and, in particular, causes interaction between the visual and vestibular nuclei to enhance the perception.

Finally, there is an important point regarding the failure to find a positive relationship between the thresholds for rotation and the oculogyral illusion since both are stimulated by angular acceleration. Two factors appear to contribute to this low relationship. The first is the very low range of thresholds found in this small group of Os. The second is that the Os with high rotation thresholds tended to exhibit much greater differences between the two indicators. Some of the Os reported that it was much easier to observe the illusion than to report rotation, and vice versa. In general, those who stated that the oculogyral illusion was easier to report showed lower thresholds with this indicator. These data suggest that there may be differences in the perceptual styles of these individuals of the sort described by Witkin et al. (1954). The perception of rotation, the oculogyral illusion, and nystagmus are commonly used as indicators of the sensitivity of the semicircular canals (Howard \& Templeton, 1966). However, to our knowledge, no direct comparisons have been made of these three indicators using the same Os. Consequently, the finding of a near zero correlation between thresholds for the perception of rotation and the oculogyral illusion suggests that each of these three effects may result from unique, highly complex processes following stimulation by angular acceleration. Additional data on all three effects with more os having a greater range of sensitivity would be necessary to settle the issue.

\section{References}

Byford, G. H. Eye movements and the optogyral illusion. Aerospace Med., 1963, 34, 119-123.

Christian, P. Ueber unbewusste Vestibulareswirkung. $Z$. fur Neurol. und Psychiat., 1939, 165, 214-219.

Clark, B. Perception of angular acceleration in man. Aerospace Med., 1967, 38, 443-450.

Clark, B., \& Graybiel, A. The effect of angular acceleration on sound localization: The audiogyral illusion. J. Psychol., 1949, $28,235-244$

Clark, B., \& Stewart, J. D. Magnitude estimates of rotational velocity during and following prolonged increasing, constant, and zero acceleration. (In preparation (a))

Clark, B., \& Stewart, J. D. Comparison of three methods to determine thresholds for the perception of passive, bodily angular acceleration. (In preparation (b))

Comsweet, T. N. The staircase method in psychophysics. Amer. J. Psychol., 1962, 75, 485-491

Graybiel, A., \& Clark, B. The validity of the oculogravic illusion as a specific indicator of otolith function. Aerospace Med., $1965,36,1173-1181$

Graybiel, A., Clark, B., MacCorquodale, K., \& Hupp, 1. Role of vestibular nystagmus in the visual perception of a moving target in the dark. Amer. J. Psychol., 1946, 59, 259-266.

Graybiel, A., \& Hupp, D. I. The oculogyral illusion. J. Ariat Med., 1946, 17, 3-27

Graybiel, A. Kerr, W. A., \& Bartley, S. H. Stimulus thresholds of the semicircular canals as a function of angular acceleration. Amer. J. Psychol., 1948, 61, 21-36.

Griffith, C. R. A historical summary of vestibular equilibrium. Unir. Illinois Bulletin, 20, No. 5, Urbana, 1922.

Guedry, F. E., Jr. The effect of visual stimulation on the duration of post-rotational apparent motion effects. J. gen. Psychol. $1950,43,313-322$

Guedry, F. E., Jr. Psychophysiological studies of vestibular function. In W. D. Neff (Ed.), Contributions to sensory physiology. New York: Academic Press, 1965.

Hallpike, C. S., \& Hood, I. D. The speed of the slow component of ocular nystagmus induced by angular acceleration of the head. Proc. Roy. Soc., Series B, 1953, 141, 216-230.

Heinemann, E. G. The relation of apparent brightness to the threshold for differences in luminance. J. exp. Psychol., 1961 $61,389-399$

Howard, I. P., \& Templeton, W. B. Human spatial orientation. New York: Wiley \& Sons, 1966.

Mann, C. W., \& Canella, C. J. An examination of the technique of cupulometry. USN School Aviation Medicine Rep. NM 001110 500. No. 42, File No. 501, Pensacola, Fiorida, 1956.

Roggeveen, L. 1., \& Nijhoff, P. The normal and pathological threshold of the perception of angular accelerations for the optogyral illusion and the turning sensation. Acta oto-laryn., $1956,46,533-541$.

van Dishoeck, H. A. E., Spoor, A., \& Nijhoff, P. The opto-gyral illusion and its relation to the nystagmus of the eyes. Acta Oto-laryn., 1954, 44, 597-607.

Whiteside, T. C. D., Graybiel, A. \& Niven, J. 1. Visual illusion of movement. BuMed Project MR005. 13-6001 Subtask 1, NASA Order No. R-93, Naval Aerospace Medical Inst., Rep. 90, Pensacola, Florida, 1963.

Witkin, H. A., Lewis, H. B., Hertzman, M., Machover, K., Meissner, P. B., \& Wapner, S. Personality through perception. New York: Harper, 1954

Note

1. This study was conducted while Dr. Clark was a National Research Council Postdoctoral Resident Research Associate at Ames Research Center on leave from the Department of Psychology, San Jose State College.

Accepted for publication Not'mler 15, 1967. 